\title{
The transition from dirty to clean industries: optimal fiscal policy and the environmental Kuznets curve
}

\author{
Steven P. Cassou ${ }^{\mathrm{a}}$ and Stephen F. Hamilton ${ }^{\mathrm{b}}$ \\ ${ }^{a}$ Department of Economics, Kansas State University, 327 Waters Hall, Manhattan, KS 66506, USA \\ ${ }^{\mathrm{b}}$ Department of Economics, University of Central Florida, P.O. Box 161400, Orlando, FL 32816, USA
}

\begin{abstract}
This paper investigates privately and socially optimal patterns of economic development in a two-sector endogenous growth model with clean and dirty goods. We consider a second-best fiscal policy framework in which distortionary taxes jointly influence economic growth and environmental quality. In this policy setting, three conditions produce an Environmental Kuznets Curve (EKC): (i) dirty output is bounded; (ii) clean output grows endogenously; and (iii) growth in the dirty sector reduces growth in the clean sector. These conditions do not arise with a consumption externality, but can emerge with a production externality. Endogenous labor supply implications are also investigated. Although not necessary for producing an EKC, endogenous labor supply provides additional linkages that produce an EKC under circumstances in which it would otherwise not appear.
\end{abstract}

Keywords: Environmental quality; Endogenous growth; Second-best policy

\section{Introduction}

Is environmental degradation a necessary by-product of economic growth? Or does society take action to control pollution as per-capita incomes rise? Encouraging recent evidence suggests that countries control the output of many pollutants as their economies grow. Following Grossman and Krueger [12,13] and Seldon and Song [29], a vast empirical literature has emerged to detail 
what has become known as the Environmental Kuznets Curve (EKC), an inverted-U shaped relationship between income and environmental degradation. ${ }^{1}$

The idea of an EKC has intuitive appeal. At early stages of industrial development, individuals may be more interested in the creation of jobs and income than in the preservation of air and water quality, while at later stages, individuals may value the environment more highly and take measures to protect it. Yet, the empirical evidence on the EKC merely describes the relationship between income and various environmental variables, without providing any explanation. This leaves open the questions of why an EKC develops, and whether the relation between pollution and income has any normative implications for policy.

A sizeable theoretical literature has developed to explain the EKC. In this literature, a nonmonotonic relationship between income and pollution arises through various mechanisms that shift either pollution supply or pollution demand over time. Copeland and Taylor [8] group this literature into four broad categories: (i) sources of growth, which shift pollution supply through composition effects in the economy that favor dirty techniques in early stages of development and favor clean techniques later on; (ii) income effects, which shift pollution demand in response to changes in per-capita income; (iii) threshold effects, which occur when pollution-control incentives increase smoothly from an initial corner solution; and (iv) increasing returns to abatement, which allow richer economies to abate at lower average cost than poorer ones. Although most papers in this literature allow for the possibility of endogenous economic growth, none of the models rely on this feature in any way to produce the EKC. Rather, the economy is predisposed in each case towards a particular combination of pollution supply and demand effects.

The goal of this paper is twofold. First, we provide an explanation for the EKC that depends fundamentally on endogenous economic growth. An advantage of this approach is that the central forces that generate the EKC emerge endogenously as equilibrium outcomes in the model, which isolates the various aspects of the economy that support and hinder development of the EKC. Second, we clarify the role of fiscal policy in guiding the economy through a nonmonotonic pattern of environmental degradation over time. Understanding this linkage between optimal fiscal policy, environmental quality, and income is important because an arbitrary dynamic tax policy is unlikely to produce the EKC. Indeed, anecdotal evidence suggests that relatively wealthy countries, which tend to have cleaner urban air and cleaner river basins than middle-income and poorer countries, also have more stringent environmental regulations and stricter enforcement of environmental laws. We consider optimal fiscal policy in a second-best framework with distorting taxes, which allows us to address the normative implications of the EKC in a realistic policy setting where corrective taxes jointly influence economic growth and environmental quality. ${ }^{2}$

Our mechanism for the EKC relates to endogenous growth as follows. The economy is comprised of two goods-producing sectors, which we label "clean" and "dirty." Production in each sector relies on inputs of capital, labor, and environmental quality. Capital employed in the

\footnotetext{
${ }^{1}$ For a survey of this literature, see Levinson [20].

${ }^{2}$ This extends a growing body of research that examines second-best policy design in static, two-sector models with distorting taxes (for a survey, see [10]). Our focus is quite different from this, however, and we confine attention to the dynamic elements of policy design by suppressing double-dividend issues.
} 
dirty sector degrades environmental quality, whereas capital employed in the clean sector does not. The connection between endogenous growth and the EKC occurs when capital used in the dirty sector generates externalities that impact productivity in each sector. ${ }^{3}$ The production externality in the dirty sector creates decreasing returns to scale over the reproducible inputs, which bounds dirty output, while the production externality in the clean sector implies that dirty capital accumulation slows the endogenous growth rate of clean output. As a result, investment in dirty capital increases future dirty consumption through a level effect, but decreases future clean consumption through a growth effect. The socially optimal stock of dirty capital balances the dynamic trade-off between these offsetting effects. Endogenous growth is important, because the cost associated with a given decrement in the clean growth rate depends on the size of the temporal consumption base in the clean sector, so that the outcome of this trade-off evolves smoothly over time as growth gradually alters the relative stock of clean capital and dirty capital in the economy. In the scenario that produces the EKC, the dirty sector is sufficiently large relative to the clean sector that accumulation of dirty capital is initially worthwhile, but unbounded endogenous growth of clean output also occurs. Pollution at first increases to favor production of the more valued dirty output, then declines, as economic growth causes the clean sector to acquire a larger share of total consumption, raising the social cost of pollution.

The model relates to threshold effects models of the EKC in the sense that the non-monotonic relationship between pollution and income operates through an evolving tension between sectoral margins. However, there are several notable differences. In threshold effects models, the incentive to control pollution grows monotonically over time, but abatement expenditures remain at zero for a number of periods until the economy passes a discrete threshold that triggers investment. In John and Pecchenino [15], abatement policy is not implemented until a threshold is breached, while in Jones and Manuelli [18] a discrete change in the tax system occurs. In Stokey [30], pollution taxes increase monotonically, but a corner solution obtains for sufficiently low levels of the tax. In our model, the EKC is not triggered by a discrete event. Instead, the EKC emerges through a continuous adjustment in the way environmental policy is administered. The optimal fiscal policy involves a non-monotonic time path for the tax on dirty capital and implements a non-trivial shift from taxes on the clean sector to taxes on the dirty sector as the economy moves through the EKC.

Our mechanism for the EKC is most similar to the threshold effect derived by Tahvonen and Salo [31] in a two-sector model with renewable and non-renewable energy sources. In their model, economic growth shifts the demand for nonrenewable resources outward over time at a non-increasing rate, while marginal extraction costs are stock-dependent and adjust over time at a rate that compounds with cumulative extraction. In early periods, the shift in demand exceeds the shift in supply, so that nonrenewable resource use (and pollution) increases, but eventually a threshold is met at which the shift in supply coincides with the shift in demand, marking the peak of the EKC. The essential difference here is that the evolving margin depends not on stock-dependent costs, but on endogenous growth. This feature produces an endogenous threshold for the EKC in which the timing and the magnitude of the

\footnotetext{
${ }^{3}$ There is considerable empirical evidence to support the role of environmental quality as a factor of production (see, e.g., $[3,25])$.
} 
environmental decline, and even the emergence or non-emergence of an EKC, depends on a set of identifiable economic conditions, such as the relative level of capitalization in the clean and dirty sectors, the endogenous growth potential in the clean sector, and the manner in which environmental quality creates value in the economy.

The linkage between endogenous growth and the environment provides insights into the types of features that underlie the EKC. We identify three conditions that must hold simultaneously for an EKC to emerge: (i) dirty output is bounded; (ii) clean output grows endogenously; and (iii) growth in the dirty sector reduces the growth rate in the clean sector. One implication of this requirement is that an EKC can occur under a production externality, but not under a consumption externality. This finding is consistent with the empirical literature, where almost all studies agree that an EKC exists for environmental pollutants with a significant connection to human health, such as water pollution, sanitation, sulphur dioxide $\left(\mathrm{SO}_{2}\right)$, oxides of nitrogen $\left(\mathrm{NO}_{x}\right)$, carbon monoxide $(\mathrm{CO})$, and suspended particulate matter, but not for such forms of pollution as municipal waste whose implications for productivity are less clear [6].

Our analysis also highlights the potential for the EKC to occur through a new channel that emerges in the labor market equilibrium. Under endogenous labor supply, a production externality that originates in either of the two sectors reduces marginal factor productivity and influences labor market participation in both sectors. Endogenous labor supply thus facilitates intersectoral spillovers that cause a production externality in a single sector of the economy to simultaneously affect productivity in all sectors, which indirectly produces all three necessary conditions for the EKC. Consequently, the EKC emerges in an economy with endogenous labor in cases where it would not otherwise occur.

The remainder of the paper is organized as follows. Section 2 presents the formal structure of the model, which we construct to allow closed-form expressions for various aspects of the economy, including the private-sector decision rules and the long-run values of the optimal tax rates. Section 3 investigates economic dynamics and describes the features that support the EKC in a context that suppresses the constraints facing a Ramsey planner. Section 4 derives conditions for the long-run social optimum and employs numerical simulation techniques to characterize the transitional dynamics associated with the EKC. ${ }^{4}$ A brief discussion follows on the role of endogenous labor supply in model.

\section{The model}

The economy consists of two production sectors, clean and dirty, that manufacture different goods using inputs of capital, labor, and environmental quality. The capital stock that produces the first type of good generates pollution, whereas capital used to produce the second type of good does not. Throughout the analysis, we refer to the good whose production generates pollution as the "dirty" good and use the term "clean" good to designate the other.

\footnotetext{
${ }^{4}$ Our simulation routine is similar to that of Mulligan and Sala-i-Martin [24], who analyze the transitional dynamics of a two-sector endogenous growth model without an environmental quality relation. Our approach also relates to that of Bovenberg and Smulders [4], who derive analytic expressions for economic transition in a linearized system that responds to an arbitrary increase in environmental standards. Our purpose is quite different, however, as our simulations are designed to characterize the socially optimal development path.
} 
The economy has both positive and negative externalities. The positive externality arises through a learning-by-doing structure that links the aggregate stock of physical capital in each sector to the stock of human capital in that sector. This structure implies that sectoral growth rates are endogenous, which is a key feature of our model for producing the EKC. The negative externality arises from capital used to produce the dirty good, as this generates pollution. Pollution degrades environmental quality, which at least potentially hinders the ability of each sector to produce goods and reduces amenity values in the economy.

The regulator seeks to internalize the effects of pollution and human capital in the economy through the use of distorting taxes on sectoral capital investment and income. In this section, we describe these elements in greater detail.

\subsection{The private sector}

The private sector consists of many identical, infinitely lived agents who act both as producers and as consumers of goods. The representative agent acquires instantaneous utility at time $t$ through the consumption of goods, $c_{t}$, and through environmental amenities, $e_{t}$, but derives disutility from contributions of labor, $l_{t}$, according to

$$
\sum_{t=0}^{\infty} \beta^{t}\left[\log \left(c_{t}-B h_{t} l_{t}^{\prime}\right)+E \log \left(\bar{e}_{t}\right)\right],
$$

where $0<\beta<1,0<B, 1<\gamma$ and $0 \leqslant E$. The utility specification employed in (1) follows Hercowitz and Sampson [14] and has the important property that the marginal rate of substitution between consumption and labor supply is independent of the consumption level, which implies that labor supply is stationary with respect to changes in the real wage. The first term in (1) can be interpreted as the reduced form of a more elaborate specification that incorporates home production, where $h_{t}$, the household's stock of human capital, exhibits productivity growth proportional to the market rate. ${ }^{5}$ Accordingly, productivity increases embodied in the accumulation of human capital over time have no effect on labor supply because of parallel increases in home production. The intertemporal elasticity of substitution in this context is $1 /(\gamma-1)$, with larger values of $\gamma$ corresponding to conditions of relatively inelastic labor supply. The second term in (1) represents an amenity value associated with environmental quality, $e_{t}=\bar{e}_{t}$, where the bar indicates average environmental quality (which is not a choice variable for the individual).

Total consumption, $c_{t}$, is a composite of consumption goods produced in the dirty and clean sectors, which is defined by

$$
c_{t}=c_{\mathrm{c}, t}^{\rho_{\mathrm{c}}} c_{\mathrm{d}, t}^{\rho_{\mathrm{d}}} \text { for } t \geqslant 0,
$$

where the subscripts $\mathrm{d}$ and $\mathrm{c}$ indicate dirty and clean goods, respectively, and $\rho_{\mathrm{c}}+\rho_{\mathrm{d}}=1$. The human capital stock is similarly distinguished across sectors,

$$
h_{t}=h_{\mathrm{c}, t}^{\rho_{\mathrm{c}}} h_{\mathrm{d}, t}^{\rho_{\mathrm{d}}} \quad \text { for } t \geqslant 0,
$$

\footnotetext{
${ }^{5}$ See Greenwood et al. [11] for further details to support this interpretation.
} 
which implies diminishing marginal returns to human capital in each sector. ${ }^{6}$ Total labor allocated to dirty and clean production activities is given by

$$
l_{t}=l_{\mathrm{c}, t}+l_{\mathrm{d}, t} \text { for } t \geqslant 0 .
$$

Production in the economy is organized as follows. In sector $j$, output is created through the employment of private inputs of capital and labor and public inputs of environmental quality according to

$$
y_{j, t}=A_{1 j} k_{j, t}^{\alpha}\left(h_{j, t} l_{j, t}\right)^{(1-\alpha)} \bar{e}_{t}^{\theta_{j}} \quad \text { for } j=\mathrm{d}, \mathrm{c}, t \geqslant 0,
$$

where $0<A_{1 j}, \alpha \in(0,1)$, and $0 \leqslant \theta_{j}$ for $j=\mathrm{d}$, c. Environmental quality is a productive factor in sector $j$ when $0<\theta_{j}$. For expositional convenience, the production functions (5) are associated with symmetric factor shares for labor and capital inputs $\left(\alpha_{d}=\alpha_{c}=\alpha\right) .^{7}$ Nonetheless, the productivity of clean and dirty goods may differ according to the sectoral coefficients $\left(A_{1 \mathrm{~d}} \neq A_{1 \mathrm{c}}\right)$ and to the extent in which environmental quality is a productive factor $\left(\theta_{\mathrm{d}} \neq \theta_{\mathrm{c}}\right)$.

In each sector, production is augmented by the accumulation of human capital. Following Arrow [1] and Romer [28], the accumulation of human capital is formulated as a process of learning by doing, in which knowledge grows proportionally to, and as a by product of, cumulative private investments in capital. ${ }^{8}$ The learning process is distinguished across sectors by allowing knowledge to accumulate independently for each type of good, so that knowledge improves the productivity of intrasectoral, but not intersectoral, goods. In equilibrium, the level of human capital in sector $j$ at time $t$ is given by

$$
h_{j, t} \equiv \bar{k}_{j, t}=k_{j, t} \quad \text { for } j=\mathrm{d}, \mathrm{c}, \quad t \geqslant 0,
$$

where $\bar{k}_{j, t}$ denotes the average level of capital stock in sector $j$ at time $t$. In (6), we suppose the number of producers is sufficiently large so that $\bar{k}_{j, t}$ is outside the choice set of the representative firm. With identical firms, it follows that $\bar{k}_{j, t}=k_{j, t}, j=\mathrm{d}$, c in equilibrium.

The stock of the dirty capital also influences environmental quality. We assume that the equilibrium value of the environment, $e_{t}=\bar{e}_{t}$, depends only on the average stock of dirty capital at time $t$. This relationship between dirty capital and the environment has two salient features: (i) dirty capital pollutes, whereas labor allocated to the dirty sector does not; and (ii) the environment serves as a limited sink for waste. The latter feature implies that, for sufficiently low levels of dirty capital, the flow of pollution is less than the assimilative capacity of the environment, so that a marginal increase in dirty production has no adverse affect on environmental quality. For levels of dirty capital above the assimilative capacity of the environment, the pollution flow exceeds the level of the environmental sink, and spillovers occur through the consumption and production channels that comprise (1) and (5). Letting $e_{\mathrm{p}}$ denote a

\footnotetext{
${ }^{6}$ For tractability, we specify symmetric composites for consumption and human capital in (2) and (3). If this assumption is relaxed, the model produces differential rates of growth for its consumption and human capital components and ultimately forces labor to a corner.

${ }^{7}$ Allowing different factor shares across the two sectors $\left(\alpha_{d} \neq \alpha_{c}\right)$ does not qualitatively change the results. These details are available from the authors upon request.

${ }^{8} \mathrm{We}$ choose the simplest possible mechanism for endogenous growth to focus the model on the dynamic tension between consumption growth and environmental quality.
} 
pristine state of the environment, environmental quality is defined by

$$
e_{t}=\operatorname{Min}\left\{A_{2} \bar{k}_{\mathrm{d}, t}^{-\sigma}, e_{\mathrm{p}}\right\}
$$

where $0<A_{2}, 0<\sigma, e_{\mathrm{p}} \in(0, \infty)$ and in equilibrium $\bar{k}_{\mathrm{d}, t}=k_{\mathrm{d}, t}$. In (7), levels of dirty capital at or below the critical value $\hat{k_{\mathrm{d}}}=\left(\frac{A_{2}}{e_{\mathrm{p}}}\right) \frac{1}{\sigma}$ are associated with a pristine environment. For values of dirty capital above $\hat{k_{\mathrm{d}}}$, environmental quality is inversely related to the dirty capital stock.

For many situations, the environmental specification (7) defines two stylized regions of economic development. Where applicable, we divide the time horizon into what we refer to as a "development region" in periods $t=0, \ldots, \hat{t}$, and an "advanced region" in periods $t=\hat{t}+1, \ldots, \infty .^{9}$ In the development region, polluting capital stocks are small relative to the size of the environmental sink, $k_{\mathrm{d}, t}<\hat{k_{\mathrm{d}}}$, and dirty capital accumulation has no environmental implications. If dirty capital grows in the development region, then at some date $\hat{t}$ (determined by the model parameters) $k_{\mathrm{d}, \hat{t}}=\hat{k}_{\mathrm{d}}$ and the economy enters the advanced region of development. In the advanced region, the negative externality channels in (1) and (5) increase the social cost of further dirty growth. ${ }^{10}$

To complete the specification of the private market, we follow [14] and formulate the dynamic process of capital accumulation as

$$
k_{j, t+1}=A_{3 j} k_{j, t}^{1-\delta} i_{j, t}^{\delta} \quad \text { for } j=\mathrm{d}, \mathrm{c}, \quad t \geqslant 0
$$

where $0<\delta \leqslant 1$. The evolution of the capital stock in (8) reflects an adjustment cost character to new investment similar to that described in Lucas and Prescott [21].

Agents in the private sector take initial endowments of dirty and clean capital stocks, $k_{j, 0}, j=$ $\mathrm{d}$, c, as given and choose $\left\{c_{j, t}, l_{j, t}, i_{j, t}, k_{j, t+1}, j=\mathrm{d}, \mathrm{c}\right\}_{t=0}^{\infty}$ to maximize (1) subject to (2)-(5), (8), and the sectoral budget constraints

$$
c_{j, t}+\left(1+\tau_{j, t}\right) i_{j, t}=\left(1-\tau_{y, t}\right) y_{j, t} \quad \text { for } j=\mathrm{d}, \mathrm{c}, \quad t \geqslant 0,
$$

where $\tau_{y, t}$ is the income tax and $\tau_{j, t}, j=\mathrm{d}, \mathrm{c}$ are sector-specific investment taxes levied on dirty and clean capital units at time $t .{ }^{11}$ The specification of the sectoral budget constraints in (9) simplifies the model by allowing the two sectors to influence each other only through the environmental externality and through consumer involvement in the labor market. Together with the government budget constraint given by (14) below, this specification eliminates the possibility that income in one sector is used, temporarily, to cross-subsidize development of the other.

\footnotetext{
${ }^{9}$ Such terminology is appropriate for situations in which the dirty capital stock grows for $k_{\mathrm{d}, t}<\hat{\mathrm{d}_{\mathrm{d}}}$ and upon passing $\hat{k_{\mathrm{d}}}$ never again falls below it. We show below this will be the outcome for all optimal policy situations in which dirty capital grows for $k_{\mathrm{d}, t}<\hat{k_{\mathrm{d}}}$, including the interesting one associated with the EKC.

${ }^{10}$ The environmental sink serves two main purposes in the model. First, it creates an initial development region that allows clean and dirty capital stocks to grow endogenously to various levels at $\hat{t}$. At this time, the forces that guide development in the advanced economy would be identical if we considered, instead, a model which began with an exogenous capital endowment. Second, the environmental sink is convenient for simulation purposes, as it stabilizes the dirty sector at a long-run steady-state when the long-run social optimum involves pristine environmental quality.

${ }^{11} \mathrm{We}$ do not constrain the respective tax instruments to be non-negative, which allows us to consider cases in which subsidization is optimal (e.g., a sector $j$ investment tax credit).
} 


\subsection{The private-sector decision rules}

The private-sector decision rules for investment, consumption, and labor are

$$
\begin{aligned}
& i_{j, t}=a \frac{\left(1-\tau_{y, t}\right)}{\left(1+\tau_{j, t}\right)} y_{j, t} \quad \text { for } j=\mathrm{d}, \mathrm{c}, \\
& c_{j, t}=\left(1-\tau_{y, t}\right)(1-a) y_{j, t} \quad \text { for } j=\mathrm{d}, \mathrm{c}, \\
& l_{j, t}=\rho_{j} l_{t}, \\
& l_{t}= \begin{cases}\left(\Gamma\left(1-\tau_{y, t}\right) e_{\mathrm{p}}^{\Theta}\right)^{\frac{1}{\gamma+\alpha-1}} & \text { for } k_{\mathrm{d}, t} \leqslant \hat{k_{\mathrm{d}}}, \\
\left(A_{2}^{\Theta} \Gamma\left(1-\tau_{y, t}\right) k_{\mathrm{d}, t}^{-\sigma \Theta}\right)^{\frac{1}{\gamma+\alpha-1}} & \text { for } k_{\mathrm{d}, t}>\hat{k_{\mathrm{d}}},\end{cases}
\end{aligned}
$$

where $a=\frac{\beta \delta \alpha}{1-\beta(1-\delta)}, \Gamma=\left(\frac{1-\alpha}{B \gamma}\right)\left(A_{1 \mathrm{c}} \rho_{\mathrm{c}}^{1-\alpha}\right)^{\rho_{\mathrm{c}}}\left[A_{1 \mathrm{~d}} \rho_{\mathrm{d}}^{1-\alpha}\right]^{\rho_{\mathrm{d}}}$, and $\Theta=\left[\theta_{\mathrm{c}} \rho_{\mathrm{c}}+\theta_{\mathrm{d}} \rho_{\mathrm{d}}\right] .{ }^{12}$

Several features of these decision rules are important. First, notice that the consumption and investment decision rules in (10) and (11) are functions of current tax rates only. This implies that there are no anticipation effects in the private-sector decision rules and, consequently, no time inconsistency issues in the social program that incorporates them. Second, notice that environmental quality enters the labor decision rule directly in (13) through the production externality. An increase in the dirty capital stock beyond $k_{\mathrm{d}, \hat{t}}=\hat{k}_{\mathrm{d}}$ decreases environmental quality, which reduces marginal factor productivity and correspondingly decreases the equilibrium rate of labor market participation. The scaling factor for this equilibrium labor market response, $\Theta$, is a weighted average of sectoral production externalities linked to labor supply through the composite consumption good. Under endogenous labor supply, a production externality in one sector jointly influences production in all goods-producing sectors of the economy.

\subsection{The government sector}

The government engages in two types of activities. First, the government purchases goods at a level denoted by $g_{t} \geqslant 0$, which are non-productive. The level of government purchases is the outcome of a political process not explicitly modeled here, and this may include the provision of other public goods not central to the present model (e.g., national defense). Second, the government engages in corrective policy designed to address the pollution externalities and a human-capital externality. The first activity, which is not essential to the model, is suppressed by treating the level of government goods purchases to be exogenous to the regulator.

The government regulator manages the externalities with three tax instruments, an income tax, $\tau_{y, t}$, and sectoral capital investment taxes, $\tau_{j, t}, j=\mathrm{d}$, c. In general, the positive human-capital externality requires subsidies to sectoral capital investment while the negative environmental externalities require an off-setting tax on dirty capital investment. The government regulator

\footnotetext{
${ }^{12}$ The derivation of these rules, as well as other analytical results in the paper, are contained in a technical appendix that is available from the authors upon request.
} 
finances these corrective policies, as well as the (exogenous) level of non-productive spending, through the use of the income tax. We assume the government runs a balanced budget at each date,

$$
g_{t}=\tau_{\mathrm{c}, t} i_{\mathrm{c}, t}+\tau_{\mathrm{d}, t} i_{\mathrm{d}, t}+\tau_{y, t}\left(y_{\mathrm{c}, t}+y_{\mathrm{d}, t}\right) \quad \text { for } t \geqslant 0 .
$$

The specification of a period-by-period balanced budget constraint in (14) facilitates the analysis of optimal fiscal policy in a second-best setting. Without this temporal budget balance, a dynamic Ramsey planner would use intertemporal government savings to levy arbitrarily large taxes on the initial capital endowment, which is inelastically supplied, then disburse these assets through capital and income subsidies for the remainder of time. ${ }^{13}$ Although this is an interesting possibility, we believe the period-by-period budget balance constraint comes closer to the type of budget constraint actually facing environmental policy makers.

Finally, we assume that non-productive government spending grows in proportion to the total level of output according to $g_{t}=\phi\left(y_{\mathrm{c}, t}+y_{\mathrm{d}, t}\right)$, where $\phi \geqslant 0$. Under this restriction, spending remains a constant share of output over time, so that $\phi$ can be interpreted as an administrative loss parameter. If the government sector entails no administrative loss $(\phi=0)$, then the model reduces to one in which taxes and subsidies serve a purely corrective role.

\section{Fiscal policy and economic dynamics}

In this section we investigate how fiscal policy impacts output and growth in the development and advanced regions. In the first subsection, no restrictions are placed on policy, so the implications can be interpreted as the outcome of an arbitrary exogenous policy. Next we derive the implications of a constant fiscal policy program. By focusing on exogenous policy we are able to illustrate the fundamental tensions of the economy arising from the pollution and learning-bydoing externalities. In Section 4, we examine the problem of a Ramsey planner who weighs each of these tensions, and, in so doing, may design fiscal policy to create an EKC.

\subsection{Production and growth implications}

Substitution of (13) and (12) into (5) yields equilibrium output in sector $j$ of

$$
y_{j, t}= \begin{cases}\Delta_{j}\left(1-\tau_{y, t}\right)^{\frac{1-\alpha}{\gamma+\alpha-1}} e_{\mathrm{p}}^{\varepsilon_{j}} k_{j, t} & \text { for } k_{\mathrm{d}, t} \leqslant \hat{k_{\mathrm{d}}}, \\ A_{2}^{\varepsilon_{j}} \Delta_{j}\left(1-\tau_{y, t}\right)^{\frac{1-\alpha}{\gamma+\alpha-1}} k_{\mathrm{d}, t}^{-\sigma \varepsilon_{j}} k_{j, t} & \text { for } k_{\mathrm{d}, t}>\hat{k_{\mathrm{d}}},\end{cases}
$$

where $\Delta_{j}=A_{1 j} \rho_{j}^{1-\alpha} \Gamma$ and $\varepsilon_{j}=\theta_{j}+\Theta\left(\frac{1-\alpha}{\gamma+\alpha-1}\right) \geqslant 0$ for $j=\mathrm{d}$, c. Two features of (15) deserve emphasis. First, a consumption externality does not affect output, whereas a production externality does. This is because private consumption and environmental quality are separable components of utility. Second, notice that the production externality enters each output expression through both a direct component, $\theta_{j}$, and an indirect component that depends on the

\footnotetext{
${ }^{13}$ See, for example, [16].
} 
magnitude of the composite environmental production effect, $\Theta$. Even in the case in which the environment is not necessary for the production of good $j\left(\theta_{j}=0\right)$, the level of environmental quality nonetheless has real economic effects on the equilibrium output in sector $j$ when a production externality affects the other good. This feedback occurs as a result of a labor market equilibrium with endogenous labor supply. When labor supply is endogenous in (13), the labor market allocation responds to various features of the economy that influence its marginal return, including the income tax rate, and in the case of a production externality, the level of environmental quality. Under a production externality, the environment has a positive effect on labor market productivity in at least one sector of the economy, so that a decline in environmental quality results in a smaller equilibrium labor market allocation, reducing output in both sectors. The indirect component of the production externality in (15) incorporates both production sectors, as each sector competes for the common labor input.

An expression for the growth rate at time $t$ can be obtained by substituting (15) into (10) and combining this expression with (8). This yields

$$
\mu_{j, t}= \begin{cases}A_{3 j}\left(a \Delta_{j}\right)^{\delta}\left(1-\tau_{y, t}\right)^{\frac{\delta \gamma}{\gamma+\alpha-1}}\left(1+\tau_{j, t}\right)^{-\delta} e_{\mathrm{p}}^{\delta \varepsilon_{j}}-1 & \text { for } k_{\mathrm{d}, t} \leqslant \hat{k_{\mathrm{d}}}, \\ A_{2}^{\delta \varepsilon_{j}} A_{3 j}\left(a \Delta_{j}\right)^{\delta} e_{t}^{\delta \varepsilon_{j}}\left(1-\tau_{y, t}\right)^{\frac{\delta \gamma}{\gamma+\alpha-1}}\left(1+\tau_{j, t}\right)^{-\delta} k_{\mathrm{d}, t}^{-\sigma \delta \varepsilon_{j}}-1 & \text { for } k_{\mathrm{d}, t}>\hat{k_{\mathrm{d}}},\end{cases}
$$

where $\mu_{j, t} \equiv \frac{k_{j, t+1}-k_{j, t}}{k_{j, t}}$ denotes the sector $j$ growth rate. Notice that each sector obtains balanced growth under constant tax policy in the development region, as $k_{\mathrm{d}, t} \leqslant \hat{k_{\mathrm{d}}}$ for $t \leqslant \hat{t}$. In the advanced region of the economy $(t>\hat{t})$, the sectoral growth rates decline with dirty capital accumulation whenever the stock of dirty capital exceeds $\hat{k}_{\mathrm{d}}$. Nonetheless, the clean sector obtains balanced growth under constant taxes for any steady-state level of dirty capital $\left(k_{\mathrm{d}, t}=k_{\mathrm{d}, \mathrm{ss}}\right)$. We elaborate on this possibility in the following section.

Expression (16) also reveals the relative growth rate of the clean and dirty sectors. For example, in an economy characterized by symmetric environmental production externalities $\left(\theta_{\mathrm{d}}=\theta_{\mathrm{c}}=\theta\right)$, the sectoral growth rates satisfy

$$
\mu_{\mathrm{c}, t} \gtreqless \mu_{\mathrm{d}, t} \Leftrightarrow \frac{A_{\mathrm{cc}}}{A_{1 \mathrm{~d}}}\left(\frac{A_{3 \mathrm{c}}}{A_{3 \mathrm{~d}}}\right)^{\frac{1}{\delta}}\left(\frac{\rho_{\mathrm{c}}}{\rho_{\mathrm{d}}}\right)^{1-\alpha} \gtreqless \frac{1+\tau_{\mathrm{c}, t}}{1+\tau_{\mathrm{d}, t}} .
$$

If the fiscal policy does not discriminate between capital types $\left(\tau_{\mathrm{c}, t}=\tau_{\mathrm{d}, t}=\tau_{t}\right)$, then dirty output growth exceeds that of clean output growth in (17) for various combinations of the following circumstances: (i) the dirty industry is more productive than the clean industry $\left(A_{1 \mathrm{c}}<A_{1 \mathrm{~d}}\right)$; (ii) dirty capital is more readily created than clean capital $\left(A_{3 \mathrm{c}}<A_{3 \mathrm{~d}}\right)$; and (iii) dirty goods are more highly valued in consumption $\left(\rho_{\mathrm{c}}<\rho_{\mathrm{d}}\right)$. Each case is consistent with an economy that, absent environmental externalities, devotes the majority of its resources to production of the dirty good.

\subsection{Constant fiscal policy}

In this section we examine economic behavior under constant fiscal policy. Under constant taxes, the dynamics of the model depend on the level of economic development. In the initial development region $t \leqslant \hat{t}$, the stock of dirty capital is sufficiently low that the environment fully 
assimilates all pollution so that $e_{t}=e_{\mathrm{p}}$ and balanced growth occurs in each sector according to (16). If the dirty sector growth rate is positive in the development region (the interesting case), then the stock of dirty capital eventually reaches $k_{\mathrm{d}, \hat{t}}=\hat{k}_{\mathrm{d}}$ at date $\hat{t}$. At this time, the economy enters the advanced region. Accumulation of dirty capital beyond $\hat{k}_{\mathrm{d}}$ degrades the environment and influences utility through the negative externality channels that enter utility directly in (1) and indirectly through private consumption in (11) and (15).

In the advanced region of development $(t>\hat{t})$, sectoral productivity depends on the nature of the externality. Under a pure consumption externality $\left(E>0, \varepsilon_{j}=0\right.$ for $\left.j=\mathrm{c}, \mathrm{d}\right)$, production in each sector involves constant returns over the reproducible factors for all $k_{\mathrm{d}, t}>\hat{k}_{\mathrm{d}}$ and consequently a balanced growth rate holds in (16) for both sectors, regardless of the level of dirty capital. Depending on the private value of each type of good and on the level of taxes, the balanced growth rate in each sector is positive, negative, or zero. If taxes are set to encourage both types of capital creation in the advanced economy, then a pattern of industrial development arises that is characterized by balanced growth of clean and dirty goods and a perpetual decline in environmental quality for all $t>\hat{t}$.

Under a production externality $\left(\varepsilon_{j}>0\right.$ for $\left.j=\mathrm{c}, \mathrm{d}\right)$, two salient features emerge in the advanced economy $(t>\hat{t})$. First, investment that increases the stock of dirty capital to $k_{\mathrm{d}, t}>\hat{k}_{\mathrm{d}}$ negatively affects productivity and growth in the clean sector when $\varepsilon_{\mathrm{c}}>0$. This implies that the potential for endogenous growth in the clean sector depends on the time path for dirty capital in the advanced economy. Endogenous growth of clean output may occur in (16) under pristine environmental quality that otherwise would not occur at lower levels of environmental quality. Second, the dirty sector exhibits bounded growth when $\varepsilon_{\mathrm{d}}>0$, as this entails decreasing returns to scale over the reproducible inputs for $k_{\mathrm{d}, t}>\hat{k}_{\mathrm{d}}$. The model thus produces Solow-type dynamics in (16) that ultimately lead the dirty capital stock to a steady state for any levels of the taxes. Moreover, with endogenous labor supply, $\varepsilon_{\mathrm{d}}>0$ even when environmental quality is entirely non-productive in the creation of dirty goods (i.e., $\theta_{\mathrm{d}}=0$ ), and $\varepsilon_{\mathrm{c}}>0$ even when environmental quality is entirely non-productive in the creation of clean goods (i.e., $\theta_{\mathrm{c}}=0$ ). This conclusion holds because a production externality links sectoral outputs through the labor supply decision (13).

Under a production externality, the steady-state equilibrium in the dirty goods sector is found by substituting (15) and (10) into (8). Making use of the steady-state condition $k_{\mathrm{d}, t+1}=k_{\mathrm{d}, t}=$ $k_{\mathrm{d}, \mathrm{ss}}$,

$$
k_{\mathrm{d}, \mathrm{ss}}=\left(A_{3 \mathrm{~d}}\right)^{\frac{1}{\delta \sigma_{\mathrm{d}}}}\left(A_{2}\right)^{\frac{1}{\sigma}}\left(a \Delta_{\mathrm{d}}\right)^{\frac{1}{\sigma \varepsilon_{\mathrm{d}}}}\left(1-\tau_{y}\right)^{\frac{\gamma}{\sigma \varepsilon_{\mathrm{d}}(\gamma+\alpha-1)}}\left(1+\tau_{\mathrm{d}}\right)^{\frac{-1}{\sigma \varepsilon_{\mathrm{d}}}} .
$$

Notice that an increase in either the income tax or the tax on dirty capital reduces the steady-state equilibrium level of dirty capital.

A steady-state level of the dirty capital stock implies a corresponding steady state for environmental quality. Substituting (18) into (8), we obtain

$$
e_{\mathrm{ss}}=A_{3 \mathrm{~d}}^{\frac{-1}{\delta_{\mathrm{d}}}}\left(a \Delta_{\mathrm{d}}\right)^{\frac{-1}{\varepsilon_{\mathrm{d}}}}\left(1-\tau_{y}\right)^{\frac{-\gamma}{\varepsilon_{\mathrm{d}}(\gamma+\alpha-1)}}\left(1+\tau_{\mathrm{d}}\right)^{\frac{1}{\varepsilon_{\mathrm{d}}}} .
$$

To characterize the effect of the fiscal policy parameters on clean-sector growth, substitute (19) into (16) and set $\tau_{y, t}=\tau_{y}$ and $\tau_{\mathrm{c}, t}=\tau_{\mathrm{c}}$. This produces a balanced growth rate in the clean sector 
given by

$$
\mu_{\mathrm{c}}=A_{3 \mathrm{c}}\left(a \Delta_{\mathrm{c}}\right)^{\delta} A_{3 \mathrm{~d}}^{\frac{-\varepsilon_{\mathrm{c}}}{\varepsilon_{\mathrm{d}}}}\left(a \Delta_{\mathrm{d}}\right)^{\frac{-\delta \varepsilon_{\mathrm{c}}}{\varepsilon_{\mathrm{d}}}}\left(1-\tau_{y}\right)^{\frac{\delta \gamma\left(\theta_{\mathrm{d}}-\theta_{\mathrm{c}}\right)}{\varepsilon_{\mathrm{d}}(\gamma+\alpha-1)}}\left(1+\tau_{\mathrm{d}}\right)^{\frac{\delta \varepsilon_{\mathrm{c}}}{\varepsilon_{\mathrm{d}}}}\left(1+\tau_{\mathrm{c}}\right)^{-\delta}-1 .
$$

Notice in (20) that the production externality manifests itself through two independent tax incentives. First, an increase in the tax on dirty capital reduces the steady-state stock of dirty capital in (18), which improves environmental quality and increases the rate of clean output growth. Second, an increase in the income tax, $\tau_{y}$, proportionally reduces both types of investment in (10). The direct effect of a higher income tax is to reduce clean sector growth, but its indirect effect is to decrease the steady-state level of the stock of dirty capital in (18), which improves environmental quality and facilitates clean growth. The overall impact of an increase in the income tax depends on the distribution of the production effect across the two sectors. If $\theta_{\mathrm{c}}>\theta_{\mathrm{d}}$, the indirect effect dominates the direct effect, and a larger income tax actually stimulates investment and growth in the clean sector.

\section{Optimal fiscal policy and the EKC}

We consider a dynamic tax structure that originates from the class of second-best optimal policy programs first considered by Ramsey [27]. ${ }^{14}$ The policy structure is one in which the regulator is a dominant market participant who takes the private-sector decision rules, the market equilibrium conditions, and the various externalities as constraints in the social program. The regulator's optimization problem is formulated as the selection of choice variables $\left\{c_{j, t}, l_{j, t}, i_{j, t}, k_{j, t+1}, j=\mathrm{d}, \mathrm{c}\right\}_{t=0}^{\infty}$ and policy variables $\left\{\tau_{y, t}, \tau_{j, t}, j=\mathrm{d}, \mathrm{c}\right\}_{t=0}^{\infty}$ to maximize (1) subject to (2)-(13).

It is analytically convenient to eliminate variables in the objective function through substitution of the constraints. Specifically, it is possible to reduce the social program to one in which the regulator chooses a sequence of optimal values $\left\{\tau_{y, t}, k_{j, t+1}, j=\mathrm{d}, \mathrm{c}, t \geqslant 0\right\}$, which are then used to recover the sequence of allocations $\left\{c_{j, t}, l_{j, t}, i_{j, t}, j=\mathrm{d}, \mathrm{c}\right\}_{t=0}^{\infty}$ and policy variables $\left\{\tau_{j, t}, j=\mathrm{d}, \mathrm{c}\right\}_{t=0}^{\infty}$ that comprise the social optimum. Making use of the private-market decision rules (10)-(13), the social problem is to

$$
\operatorname{Max}_{\tau_{y, t}, k_{j, t+1}} \sum_{t=0}^{\infty} \beta^{t}\left\{\log \left(\frac{\gamma(1-a)+\alpha-1}{\gamma}\left(1-\tau_{y, t}\right) y_{\mathrm{c}, t}^{\rho_{\mathrm{c}}} y_{\mathrm{d}, t}^{\rho_{\mathrm{d}}}\right)+E \log \left(e_{t}\right)\right\}
$$

subject to the government budget constraint,

$$
g_{t}=\left[a+(1-a) \tau_{y, t}\right]\left(y_{\mathrm{c}, t}+y_{\mathrm{d}, t}\right)-i_{\mathrm{c}, t}-i_{\mathrm{d}, t},
$$

and the private-market equilibrium conditions (7), (8), and (15).

The Ramsey planner takes the level of government spending as exogenous. The government revenue needed at each date is a constant faction of output, $g_{t}=\phi\left(y_{\mathrm{d} t}+y_{\mathrm{c} t}\right)$, but this is treated as

\footnotetext{
${ }^{14}$ There has been considerable recent work investigating these kinds of programs, including Lucas and Stokey [22], Jones et al. [16,17], Zhu [32], and Cassou and Lansing [5].
} 
exogenous to the regulator by incorporating this information as an equilibrium condition after the first-order conditions are derived. ${ }^{15}$

Substituting (7), (8), and (15) into (21) and (22), the first-order necessary conditions for this problem are

$$
\begin{aligned}
\frac{\partial L_{g}(\cdot)}{\partial \tau_{y, t}}:\left(\frac{\gamma}{\gamma+\alpha-1}\right)= & \lambda_{g, t}\left[(1-a)\left(y_{\mathrm{c}, t}+y_{\mathrm{d}, t}\right)\left(1-\tau_{y, t}\right)\right. \\
& \left.-\left[a+(1-a) \tau_{y, t}\right]\left(\frac{1-\alpha}{\gamma+\alpha-1}\right)\left(y_{\mathrm{c}, t}+y_{\mathrm{d}, t}\right)\right],
\end{aligned}
$$

$$
\begin{aligned}
& \frac{\partial L_{g}(\cdot)}{\partial k_{\mathrm{c}, t+1}}: \lambda_{g, t}\left(\frac{1}{\delta}\right) i_{\mathrm{c}, t} \\
& \quad=\beta \rho_{\mathrm{c}}+\beta \lambda_{g, t+1}\left[\left[a+(1-a) \tau_{y, t+1}\right] y_{\mathrm{c}, t+1}+\left(\frac{(1-\delta)}{\delta}\right) i_{\mathrm{c}, t+1}\right]
\end{aligned}
$$

$$
\frac{\partial L_{g}(\cdot)}{\partial k_{\mathrm{d}, t+1}}:
$$

$$
\left\{\begin{array}{cc}
\lambda_{g, t}\left(\frac{1}{\delta}\right) i_{\mathrm{d}, t} & \\
=\beta \rho_{\mathrm{d}}+\beta \lambda_{g, t+1}\left[\left[a+(1-a) \tau_{y, t+1}\right] y_{\mathrm{d}, t+1}\right. & \text { for } k_{\mathrm{d}, t} \leqslant \hat{k}_{\mathrm{d}} \\
\left.+\left(\frac{(1-\delta)}{\delta}\right) i_{\mathrm{d}, t+1}\right] & \\
\lambda_{g, t}\left(\frac{1}{\delta}\right) i_{\mathrm{d}, t} & \\
=\beta\left(\rho_{\mathrm{d}}-\sigma\left(\frac{\gamma \Theta}{\gamma+\alpha-1}+E\right)\right) & \text { for } k_{\mathrm{d}, t}>\hat{k}_{\mathrm{d}} \\
+\beta \lambda_{g, t+1}\left[\left[a+(1-a) \tau_{y, t+1}\right]\left(\left(1-\sigma \varepsilon_{\mathrm{d}}\right) y_{\mathrm{d}, t+1}-\sigma \varepsilon_{\mathrm{c}} y_{\mathrm{c}, t+1}\right)\right. & \\
\left.+\left(\frac{(1-\delta)}{\delta}\right) i_{\mathrm{d}, t+1}\right] & \\
\frac{\partial L_{g}(\cdot)}{\partial \lambda_{g, t}:\left[a+(1-a) \tau_{y, t}\right]\left(y_{\mathrm{c}, t}+y_{\mathrm{d}, t}\right)-i_{\mathrm{c}, t}-i_{\mathrm{d}, t}=g_{t} .}
\end{array}\right.
$$

The first-order conditions for sectoral capital accumulation in (24) and (25) describe similar consumption and investment considerations in the development region. In the advanced region of the economy, however, external effects emerge in (25) for $k_{\mathrm{d}, t}>\hat{k_{\mathrm{d}}}$ that influence the marginal utility of dirty goods under a consumption externality $(E>0)$ and both the marginal utility and

\footnotetext{
${ }^{15}$ This is in the spirit of Ramsey [27], where government revenue needs are exogenous and taxes are selected so as to acheive the exogenous revenue need at a minimum welfare loss.
} 
the marginal productivity of dirty capital investment under a production externality $(\Theta>0$ and $\varepsilon_{j}>0$ for $\left.j=\mathrm{d}, \mathrm{c}\right)$. The nonlinearity of the dirty capital investment condition at $\hat{k}_{\mathrm{d}}$ introduces dynamics that depend on the level of the stock of dirty capital, which makes closed-form solutions for the fiscal policy decision rules possible in only a limited range of circumstances.

In the following sections, we first investigate optimal fiscal policy under a consumption externality, then extend this analysis to consider a production externality. Throughout, we confine attention to circumstances in which the optimal policy generates endogenous growth in each sector during the development region of the economy.

\subsection{A consumption externality}

Consider the case in which environmental quality contributes only amenity value in the economy $\left(E>0\right.$ and $\varepsilon_{j}=0$ for $\left.j=\mathrm{d}, \mathrm{c}\right)$. In this case, (15) implies constant returns to the reproducible factors of production in both sectors, and endogenous growth is therefore feasible for both sectors in the advanced region. Given that endogenous growth of the clean sector is desirable in the development region, it remains so in the advanced economy. Endogenous growth in the dirty sector may no longer occur at time $\hat{t}$, however, as the Ramsey planner responds to the consumption externality by adjusting the tax rates, $\tau_{y, t}$ and $\tau_{\mathrm{d}, t}$, to reduce, and potentially eliminate growth in the dirty sector.

The following pattern of economic development emerges under a consumption externality. In the development region $(t \leqslant \hat{t})$, the Ramsey planner encourages growth by providing tax incentives to both sectors of the economy. Accumulation of dirty capital occurs at a positive rate until, at some time $\hat{t}$ (determined by model parameters), $k_{\mathrm{d}, \hat{t}}=\hat{k}_{\mathrm{d}}$, and the consumption externality sets in. At time $\hat{t}$, the marginal social benefit of dirty capital investment on $\hat{t}+1$ consumption falls to $\beta\left(\rho_{\mathrm{d}}-\sigma E\right) \gtreqless 0$ in (25) to account for environmental amenity values. Notice that the marginal social benefit of dirty consumption does not depend on any of the state variables in the model. This implies that the condition that determines whether or not continued endogenous growth of dirty output is socially desirable in the advanced economy remains identical for all $k_{\mathrm{d}, t}$. One of two outcomes occurs in the advanced region $(t \geqslant \hat{t})$. First, for sufficiently large values of the consumption externality $\left(\rho_{\mathrm{d}} \leqslant \sigma E\right)$, the marginal social benefit of dirty capital is (at least weakly) negative for all $k_{\mathrm{d}, t} \geqslant \hat{k_{\mathrm{d}}}$ and the Ramsey planner immediately adjusts the tax rates at $\hat{t}$ to maintain a pristine level of environmental quality for the remainder of time. Second, for less extreme values of the consumption externality $\left(\rho_{\mathrm{d}}>\sigma E\right)$, continued endogenous growth in the dirty sector may be optimal at $\hat{t}$. If so, endogenous output growth in the dirty sector remains optimal for all $t \geqslant \hat{t}$, and environmental quality declines asymptotically over time. Under either outcome, an EKC does not occur.

\subsection{Production externality}

Next consider the case in which environmental quality has only productive effects $(E=0$ and $\varepsilon_{j}>0$ for some $j=\mathrm{d}, \mathrm{c}$ ). In this case, several terms appear in the dirty capital investment condition (25) at time $\hat{t}$. The production externality now influences social investment in dirty capital both through a utility component, $\Theta$, and through sectoral productivity components, $\varepsilon_{\mathrm{c}}$ and $\varepsilon_{\mathrm{d}}$. The 
utility component operates in a manner similar to a consumption externality; indeed, if this was the only effect, the two forms of externality would be isomorphic. The sectoral productivity components differ in that they affect sectoral output levels. This creates state-dependent effects which are central to our explanation of the EKC.

The following pattern of economic development emerges under a production externality. In the initial development region $(t \leqslant \hat{t})$, the optimal policy encourages growth in both sectors of the economy until, at time $\hat{t}$, the stock of dirty capital reaches $k_{\mathrm{d}, \hat{t}}=\hat{k_{\mathrm{d}}}$ and the economy enters the advanced region of development. Several possibilities occur at this time. One possibility is that the regulator immediately sets taxes to curb dirty sector growth. Maintaining the stock of dirty capital at $k_{\mathrm{d}, \mathrm{ss}}^{*}=\hat{k_{\mathrm{d}}}$ preserves a pristine environment, and this minimizes the drag that dirty capital places on the endogenous growth of clean output in (16). To see whether such a policy is optimal, consider defections from it. There are two types of defections: one that "tightens" environmental policy by raising taxes on dirty capital; and one that "loosens" environmental policy by reducing taxes on dirty capital. ${ }^{16}$ A tightened environmental policy is clearly sub-optimal at $\hat{t}$, because this would reduce the dirty capital stock below $\hat{k}_{\mathrm{d}}$ without improving environmental quality, and we have assumed dirty growth to be optimal for a stock of dirty capital below $\hat{k}_{\mathrm{d}}$.

The remaining possibility is a defection that temporarily loosens environmental policy. Under this scenario, dirty investment continues at $\hat{t}$ at a level that increases the dirty capital stock at $\hat{t}+1$, reducing environmental quality. The marginal benefit of loosening environmental policy is the discounted stream of additional dirty consumption injected into the economy by the higher dirty capital stock. This benefit enters as a level effect in the dirty sector in the following sense. If the regulator permanently adjusts taxes to maintain a stock of dirty capital above $\hat{k}_{\mathrm{d}}$, dynamics of the type described in Section 3.2 arise, and the stock of dirty capital approaches a steady state given by (18). Growth eventually ceases in the dirty sector, because $\varepsilon_{\mathrm{d}}>0$ implies decreasing returns to scale over the reproducible inputs in (15) for $k_{\mathrm{d}, t}>\hat{k_{\mathrm{d}}}$. In the long run, only the stock of dirty capital, and consequently the level of dirty consumption, are higher under this policy, not the long-run rate of dirty growth, so that loosening environmental policy produces only a level effect on utility. The marginal cost of loosening environmental policy is the discounted steam of lost clean consumption resulting from the higher dirty capital stock. This is a growth effect. If the regulator permanently adjusts taxes to maintain a stock of dirty capital stock above $\hat{k_{\mathrm{d}}}$, environmental quality declines, which dampens the long-run endogenous growth rate in the clean sector in (16). The social value of this growth effect depends on the size of the clean consumption base over which it is compounded.

The outcome for the economy in the advanced region depends on the dynamic tension between the level effect and the growth effect. If the utility value of the growth effect exceeds that of the level effect at $\hat{t}$, then the planner immediately sets taxes to curb dirty capital accumulation at $k_{\mathrm{d}, \hat{t}+1}=\hat{k_{\mathrm{d}}}$ and emphasize clean growth. The dirty capital stock remains at $\hat{k_{\mathrm{d}}}$ while the clean capital stock grows between $\hat{t}$ and $\hat{t}+1$, and this correspondingly increases the magnitude of the

\footnotetext{
${ }^{16}$ By "tighten" and "loosen", we mean relative to a policy that maintains $k_{\mathrm{d}, t}=\hat{k_{\mathrm{d}}}$, not relative to the policy that was implemented in the development region.
} 
growth effect. Thus, the growth effect continues to exceed the level effect for all dates thereafter, and the optimal policy maintains a steady-state dirty capital stock of $k_{\mathrm{d}, \mathrm{ss}}^{*}=\hat{\mathrm{d}_{\mathrm{d}}}$.

If the level effect exceeds the growth effect at $\hat{t}$, then the optimal policy at least temporarily allows dirty capital to continue growing. The Ramsey planner must then make a nontrivial comparison at each date in the advanced economy between the discounted value of the two opposing effects arising from dirty capital investment. The dynamic outcome of this trade-off depends on the relative size of the clean and dirty temporal consumption base at each date in the advanced economy, and, because the temporal consumption base in each sector adjusts over time with changes in the capital stocks, the optimal environmental policy also evolves over time. This has important implications both for the long-run equilibrium and for the transitional pattern of development in an advanced economy.

\subsubsection{The long-run outcome}

The long-run equilibrium under a production externality depends on the dynamic outcome for the utility values associated with the growth and level effects. As noted above, if the growth effect dominates the level effect at $\hat{t}$, then it continues to dominate the level effect for all dates $t>\hat{t}$, and the economy maintains a steady-state stock of dirty capital of $k_{\mathrm{d}, \mathrm{ss}}^{*}=\hat{k}_{\mathrm{d}}$. The clean sector grows endogenously under pristine environmental quality at its potential rate and the utility value associated with the growth effect is unbounded in the long run.

If the level effect dominates the growth effect at $\hat{t}$, then one of two outcomes occurs. Either the growth effect never overtakes the level effect (in terms of its utility value), or the growth effect eventually surpasses the level effect. ${ }^{17}$ In the first case, the social optimum involves a negative long-run growth rate for the clean sector. In the second case, the long-run rate of clean output growth is positive. The dynamic outcome that ultimately prevails depends on several features of the economy at $\hat{t}$, including the social discount rate, the endogenous growth potential in the clean sector, the amount of drag environmental degradation places on clean output growth, and the relative level capitalization in the clean and dirty sectors. For a given stock of dirty capital at $\hat{t}$, a larger stock of clean capital narrows the gap between the growth effect and the level effect (in utility terms), which makes a positive long-run growth outcome for the clean sector more likely.

For $t>\hat{t}$, the growth effect evolves from its initial position with changes in the size of clean consumption base. Ultimately the direction of this change depends on the effective rate of endogenous output growth in the clean sector. The effective rate of endogenous growth of clean output, which is positive for some levels of dirty capital in the advanced economy but negative for others, depends on both the potential rate of clean sector growth under pristine environmental conditions and the degree to which dirty capital accumulation dampens clean sector growth in (16). The social discount rate maps the level effect and the growth effect into utility terms, and this also influences the outcome because each effect manifests itself differently in the dynamic pattern of future consumption. Stimulating growth creates a stream of future consumption that compounds indefinitely over time, whereas the level effect facilitates more immediate

\footnotetext{
${ }^{17}$ There is also a remote possibility that the utility values of the growth and level effects converge to the same point in the long-run, so that the clean and dirty capital stocks simultaneously approach a steady-state. This is a zero measure outcome, and we choose to ignore it here.
} 
consumption, so that a more patient planner places greater emphasis on the growth effect than a less patient one.

It may seem that if clean output growth is optimal in the development region it should always remain desirable in the advanced economy. This is not the case. The optimality conditions for clean and dirty capital investment in (24) and (25) are linked in the advanced economy, which raises the standard on how attractive the clean sector must be as a vehicle for sustained endogenous output growth. If the level effect exceeds the growth effect at $\hat{t}$, then the Ramsey planner sets environmental policy to encourage accumulation of dirty capital. In response, environmental quality declines at $\hat{t}+1$, dampening the growth rate of clean output. The clean sector always grows at $\hat{t}$ (by assumption), and continues to grow for at least some time in the advanced economy. However, if the potential endogenous growth rate in the clean sector is sufficiently small, then it is possible that environmental degradation reduces the clean growth rate below zero before the growth effect can overtake the level effect. Thus, the accumulation of dirty capital can crowd out clean sector growth that would otherwise occur without environmental feedback.

If the growth effect does not eventually overtake the level effect, the stock of dirty capital remains above $\hat{k_{\mathrm{d}}}$ indefinitely at a level that bounds economic output in both sectors. The economy remains trapped below the threshold at which cleaning up pollution makes economic sense, and the dirty sector develops to a point where the long-run rate of clean output growth is negative. ${ }^{18}$

The other possibility is that the social optimum supports a positive rate of endogenous clean output growth in the long run. This is the interesting case in which an EKC develops. At time $\hat{t}$, the level effect exceeds the growth effect and the regulator temporarily encourages accumulation of dirty capital. However, because the clean sector obtains unbounded endogenous output growth, the growth effect eventually dominates the level effect and, at this point, dirty capital disinvestment becomes desirable. The optimal fiscal policy that supports positive growth of clean output must therefore adjust tax rates in the long run to maintain a pristine environment. The long-run dirty capital stock is given by

$$
k_{\mathrm{d}, \mathrm{ss}}^{*}=\hat{k_{\mathrm{d}}}=\left(\frac{A_{2}}{e_{\mathrm{p}}}\right)^{\frac{1}{\sigma}} .
$$

The long-run equilibrium level of the tax on dirty capital (as a function of the income tax) is recovered by substituting (27) into (8) and making use of (10) and (15),

$$
\tau_{\mathrm{d}}\left(\tau_{y}\right)=a A_{3 \mathrm{~d}}^{\frac{1}{\delta}} \Delta_{\mathrm{d}}\left(1-\tau_{y}\right)^{\frac{\gamma}{\gamma+\alpha-1}} e_{\mathrm{p}}^{\varepsilon_{\mathrm{d}}}-1 \text {. }
$$

The long-run value of the dirty capital tax in (28) depends on the level of the income tax, as the tax incentive necessary to obtain a steady-state stock of dirty capital is determined jointly by these two tax rates in (18). Notice that the magnitude of the tax on dirty capital depends only on the

\footnotetext{
${ }^{18}$ This environmental trap may explain current development patterns in some countries. Although the data indicate that many developed countries have gone through an EKC period and now use cleaner production techniques, others have not, and our model provides no reassurance that the trend towards increasing pollution levels in these countries will change course as per capita income (temporarily) grows.
} 
extent of the production externality in the economy. A consumption externality does not affect the private-sector decision rules and therefore has no bearing on the equilibrium growth rate of dirty output.

As the clean sector continues to grow at this steady state, the dirty sector becomes an increasingly small part of the economy. In the limit, the long-run social optimum satisfies the equilibrium restrictions

$$
\begin{aligned}
& \lim _{t \rightarrow \infty} \frac{y_{\mathrm{d}, t}}{y_{\mathrm{c}, t}} \rightarrow 0, \\
& \lim _{t \rightarrow \infty} \frac{i_{\mathrm{d}, t}}{y_{\mathrm{c}, t}} \rightarrow 0, \\
& \lim _{t \rightarrow \infty} g_{t} \rightarrow \phi y_{\mathrm{c}, t} .
\end{aligned}
$$

Substitution of these values into the first-order conditions (23)-(26) yields

$$
\begin{aligned}
& \frac{\partial L_{g}(\cdot)}{\partial \tau_{y, t}}:\left(\frac{\gamma}{\gamma+\alpha-1}\right)=\lambda_{g, t}\left[(1-a) y_{\mathrm{c}, t}\left(1-\tau_{y, t}\right)\right. \\
& \left.-\left[a+(1-a) \tau_{y, t}\right]\left(\frac{1-\alpha}{\gamma+\alpha-1}\right) y_{\mathrm{c}, t}\right] . \\
& \frac{\partial L_{g}(\cdot)}{\partial k_{\mathrm{c}, t+1}}: \lambda_{g, t}\left(\frac{1}{\delta}\right) i_{\mathrm{c}, t} \\
& =\beta \rho_{\mathrm{c}}+\beta \lambda_{g, t+1}\left[\left[a+(1-a) \tau_{y, t+1}\right] y_{\mathrm{c}, t+1}\right. \\
& \left.+\left(\frac{(1-\delta)}{\delta}\right) i_{\mathrm{c}, t+1}\right]=0, \\
& \frac{\partial L_{g}(\cdot)}{\partial \lambda_{g, t}}:\left(a+(1-a) \tau_{y, t}\right) y_{\mathrm{c}, t}-i_{\mathrm{c}, t}-g_{t}=0 .
\end{aligned}
$$

The solution to (32)-(34) is

$$
\begin{aligned}
& i_{\mathrm{c}, t}=b_{1} y_{\mathrm{c}, t} \\
& \tau_{y}^{*}=\frac{b_{1}+\phi-a}{1-a}>0 \text { and } \tau_{\mathrm{c}}^{*}=\frac{a(1-\phi)-b_{1}}{(1-a) b_{1}}<0,
\end{aligned}
$$

where

$$
b_{1}=\frac{\delta \beta\left[\rho_{\mathrm{c}}(\gamma+\alpha-1)+\left(1-\rho_{\mathrm{c}}\right) \gamma \phi\right]}{\gamma\left[1-\beta+\delta \beta \rho_{\mathrm{c}}\right]}>0 .
$$


Notice that both the income tax rate and the clean capital tax rates approach constant values in the long-run equilibrium that do not depend on the coefficients of environmental productivity. This is because private and social investment incentives are aligned with respect to the production externality at a pristine level of environmental quality. Nonetheless, the Ramsey planner implements a corrective tax policy in the clean sector to encourage human capital creation, which involves using income tax revenue to finance a capital investment subsidy in the clean sector. ${ }^{19}$ For completeness, the optimal tax on dirty capital investment can be recovered by substituting $\tau_{y}^{*}$ into (28) to obtain

$$
\tau_{\mathrm{d}}^{*}=a A_{3 \mathrm{~d}}^{\frac{1}{\delta}} \Delta_{\mathrm{d}}\left(\frac{1-b_{1}-\phi}{1-a}\right)^{\frac{\gamma}{\gamma+\alpha-1}} e_{\mathrm{p}}^{\varepsilon_{\mathrm{d}}}-1 .
$$

\subsubsection{The short-run outcome and the EKC}

An EKC emerges in the advanced region of the economy if two properties hold. First, as the economy enters the advanced region of development, the benefit associated with increasing the stock of dirty capital must exceed the cost. Second, the growth rate of clean output must remain positive as environmental quality degrades through the upward sloping portion of the EKC until, at some point, the utility value of the growth effect coincides with that of the level effect. This marks the turning point of the EKC. When both properties hold, the Ramsey planner temporarily loosens environmental policy to encourage accumulation of dirty capital at time $\hat{t}$, and environmental quality declines. At some point, the growth effect equals, then surpasses the level effect, and the planner responds by temporarily tightening environmental policy, compeling agents to divest dirty capital to the long-run steady-state level, $k_{\mathrm{d}, \mathrm{ss}}^{*}=\hat{k}_{\mathrm{d}}$. Environmental quality trends smoothly back to the pristine level in response.

The remainder of this section illustrates the possibility of an EKC through numerical simulation. Parameters in the baseline simulation are selected according to several criteria. First, to avoid extreme solutions, environmental parameters are chosen to entail relatively modest productivity impacts in the economy. Second, the parameters that describe consumer preferences and clean sector productivity are selected to match the long-run balanced growth path of the model to several observed features of the US economy. Third, to provide a baseline simulation, symmetric parameters are chosen for dirty-sector productivity so that the initial growth incentives are equal across sectors in the development region. In later simulations, we compare the dynamic implications of this baseline calibration with results derived from alternative parameterizations of the model in which the dirty sector is either more productive than the clean sector or produces a good with relatively more desirable consumptive qualities.

The environmental parameters are selected as follows. First, to generate a modest impact of the environment on production, we choose $\theta_{\mathrm{d}}=\theta_{\mathrm{c}}=0.05$. Second, we choose a pristine level of environmental quality represented by the unit value $\left(e_{\mathrm{p}}=1\right)$, and, finally, we select parameters relating the sensitivity of the environment to the dirty capital stocks to satisfy $\sigma=1$ and $A_{2}=1$. This implies a long-run steady-state value of the dirty capital stock given by $k_{\mathrm{d}, \mathrm{ss}}^{*}=1$.

\footnotetext{
${ }^{19}$ The tax on dirty capital provides an insignificant source of government revenue in the long-run equilibrium; hence, it cannot be used to cross-subsidize clean output growth.
} 
Table 1

Calibrated parameter values

\begin{tabular}{lll}
\hline Parameter & Estimate & Calibration target \\
\hline$\rho_{\mathrm{c}}=\rho_{\mathrm{d}}$ & 0.500 & NA \\
$E$ & 0 & NA \\
$\theta_{\mathrm{c}}=\theta_{\mathrm{d}}$ & 0.050 & NA \\
$e_{\mathrm{p}}$ & 1 & NA \\
$\sigma$ & 1 & NA \\
$A_{2}$ & 1 & NA \\
$\gamma$ & 1.600 & Empirical labor supply elasticity [23]. \\
$\alpha$ & 0.400 & Average share of capital in output [7]. \\
$\phi$ & 0.212 & Average $g / y$ in the US post-war period. \\
$A_{1 \mathrm{c}}=A_{1 \mathrm{~d}}$ & 1.125 & Average $k / y=2.61,(\mathrm{durables} / \mathrm{structures} / \mathrm{equipment} / \mathrm{residential).}$. \\
$A_{3 \mathrm{c}}=A_{3 \mathrm{~d}}$ & 1.129 & Average per capita output growth $\mu=1.80 \%$. \\
$\delta$ & 0.041 & Average $i / y=0.22,(\mathrm{durables} / \mathrm{structures} / \mathrm{equipment} / \mathrm{residential).}$. \\
$B$ & 0.685 & Time in market work $0.33,[19]$. \\
$\beta$ & 0.979 & After-tax interest rate $\hat{r}=4 \%[26]$. \\
$\tau_{y}$ & 0.231 & Chosen to satisfy $(22)$. \\
$\tau_{\mathrm{c}}=\tau_{\mathrm{d}}$ & -0.084 & Effective marginal capital tax rate $0.16[2]$. \\
\hline
\end{tabular}

${ }^{\text {a }}$ The after-tax interest rate $\hat{r}$ is defined by introducing privately issued real bonds (which exist in zero net supply) into the household budget constraint. The first-order condition for bonds implies $\hat{r}=\exp (\mu-\ln \beta)-1$.

The calibration targets and the estimated parameters that comprise the baseline simulation are summarized in Table 1. The baseline simulation involves symmetric consumer tastes for clean and dirty goods, $\rho_{\mathrm{c}}=\rho_{\mathrm{d}}=0.5$, and symmetric production elasticities of $\alpha=0.4$ as advocated by Cooley and Prescott [7]. The labor supply conditions are described by $\gamma=1.6$, which corresponds to an intertemporal labor elasticity of 1.7, a value midway in the range of empirical estimates reported by Mulligan [23]. The government spending parameter $\phi$ is set equal to 0.212 to coincide with the average ratio of government expenditure to GDP over the 1970-1998 period. The remaining parameters that describe preferences and production in the baseline calibration are selected simultaneously to match the long run balanced growth path of the model to several observed moments of US post-war manufacturing data.

Fig. 1 presents simulated time paths for the variables that comprise the numerical solutions to the dynamic first-order conditions (23)-(26) in the baseline calibration model. ${ }^{20}$ The model converges to a steady-state stock of dirty capital, an equilibrium rate of balanced clean-sector growth of $\mu_{\mathrm{c}}=0.0337$, and constant tax rates given by $\tau_{y}=$ $0.4846, \tau_{\mathrm{d}}=-0.2520$, and $\tau_{\mathrm{c}}=-0.6687$. The long-run growth rate in the clean sector is considerably higher than the calibration target for per-capita output growth, which reflects the

\footnotetext{
${ }^{20}$ The model is solved using what a backwards simulation technique. This technique starts at the long run steady state and then recursively solves Eqs. (23)-(26) for earlier periods. For these simulations, the end-time conditions were given by $k_{\mathrm{c}}^{*}=1,000, k_{\mathrm{d}, \mathrm{ss}}^{*}=1, \tau_{y}^{*}=\frac{b_{1}+\phi-a}{1-a}$, and $\lambda_{g}^{*} y_{\mathrm{c}}^{*}=\frac{b_{1}(1-\beta)-\delta \beta \phi}{\delta \beta \rho_{\mathrm{c}}}$. The derivation of the long run expression involving $\lambda_{g}^{*}$ can be found in the technical appendix available from the authors.
} 
significant adjustments that take place in both the tax parameters and the environmental quality level at the second-best optimum.

The socially optimal development path in the baseline simulation is characterized by a notably U-shaped pattern of environmental decline and recovery over time. This relationship appears in Fig. 1a, which shows the time path of environmental quality. The U-shaped pattern of environmental decline and recovery in the panel accords well with the empirical regularity that

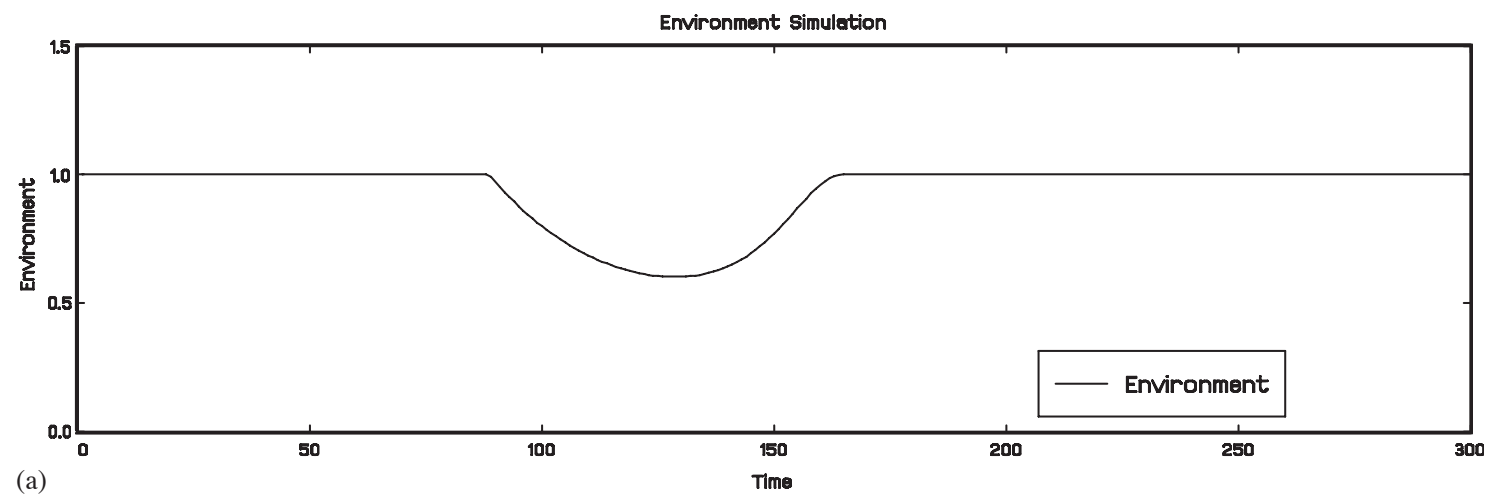

(a)

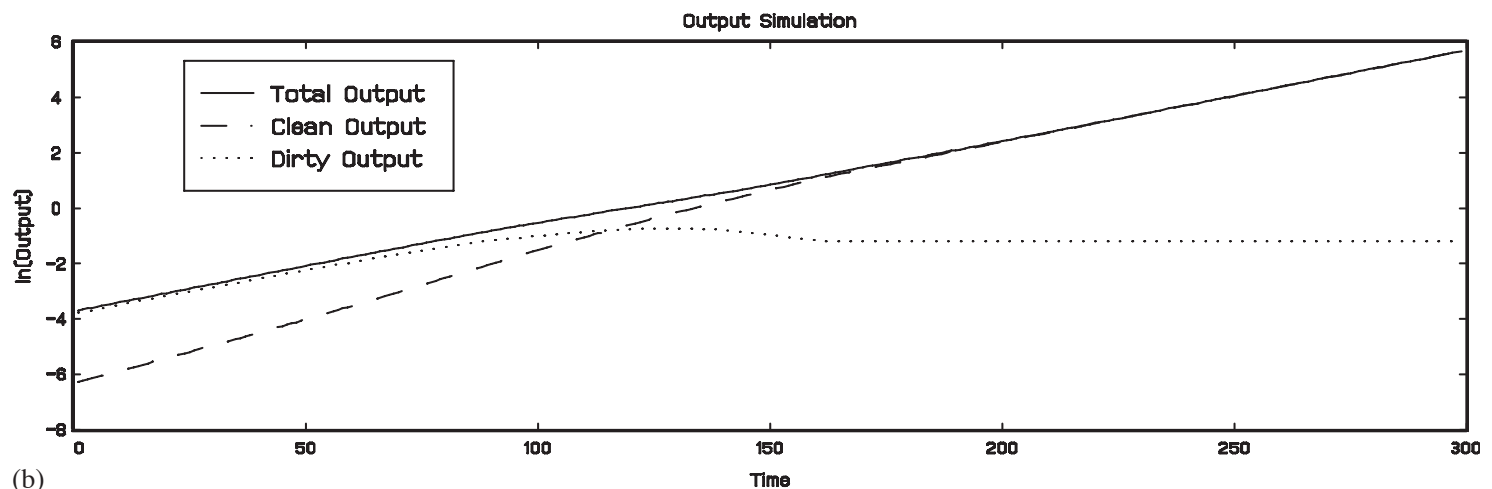

(b)

Capital Simulation

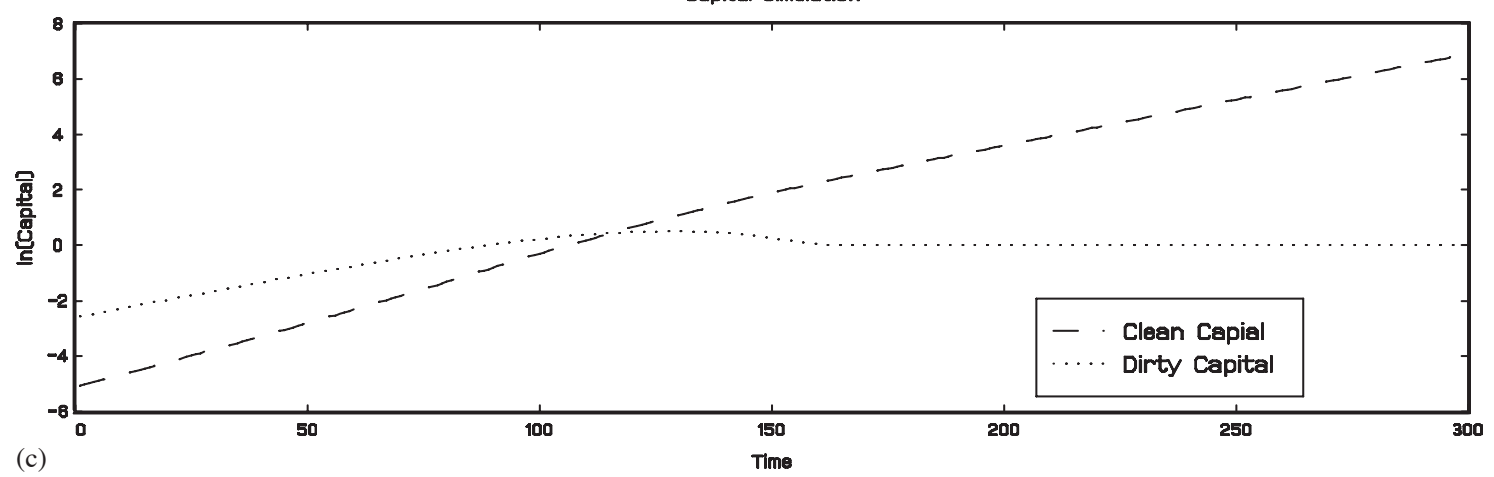

Fig. 1. 

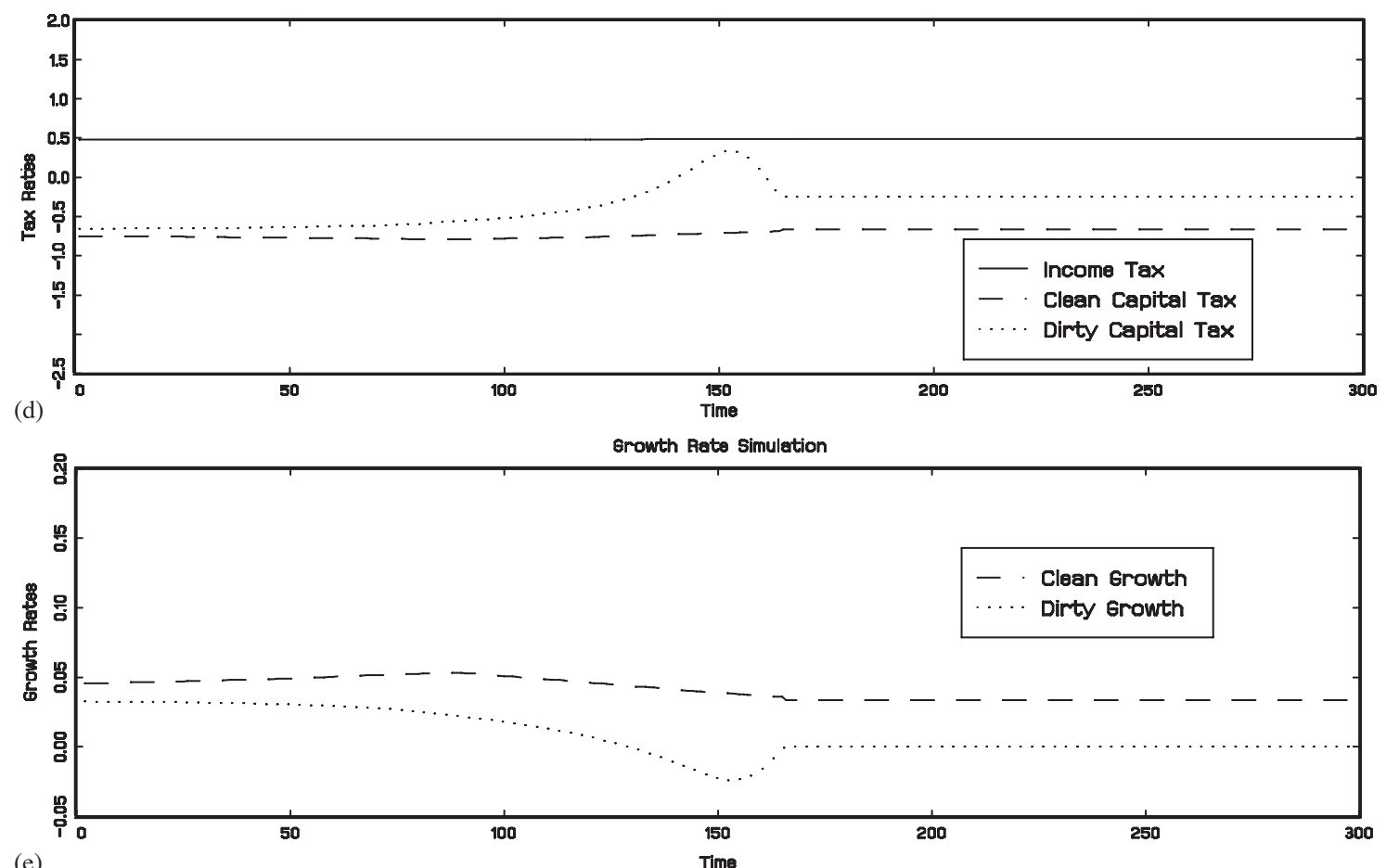

(e)

Consumption Simulation

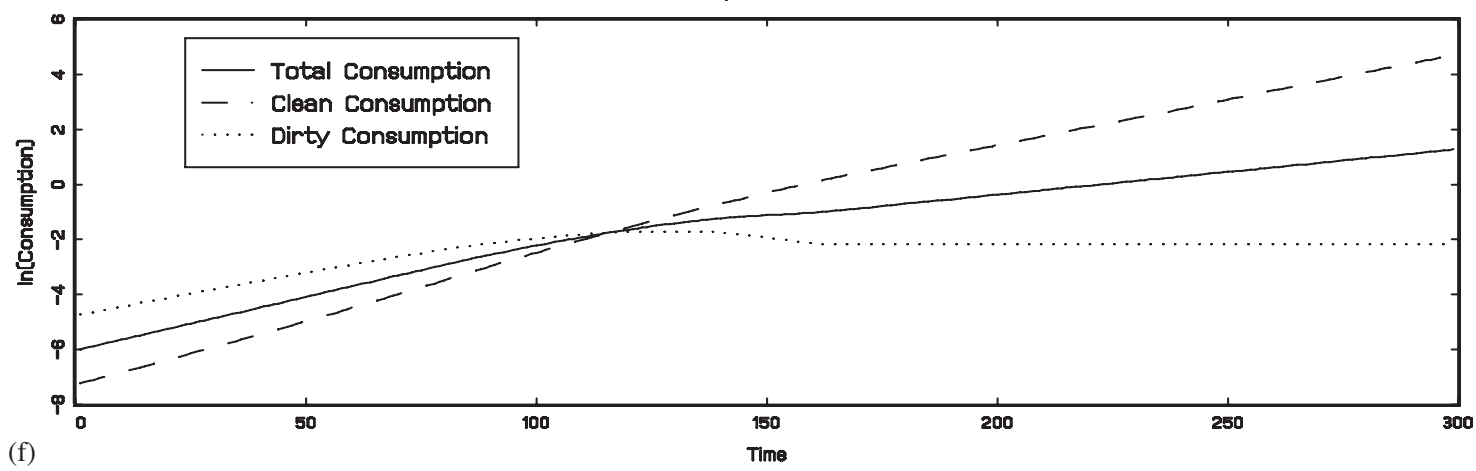

Fig. 1 (continued).

pollution at first increases then declines with per capita GDP, as Fig. 1b demonstrates a monotonic increase in per-capita income over time. ${ }^{21}$

An important feature in Fig. $1 \mathrm{~b}$ is the trend in the sectoral composition of output (and income) in the economy. At the beginning of the simulated horizon, the dirty sector is the primary source of output in the economy; however, output in the clean sector acquires a larger share of total output throughout the simulated horizon, and the time paths cross approximately at the turning

\footnotetext{
${ }^{21}$ The standard depiction of the EKC plots environmental quality against income. Here, because income increases monotonically over the horizon, it is more constructive to view the evolution of each variable over time.
} 
point of the EKC. This suggests that the EKC may depend not just on per-capita income in a country, but also on the composition of output across polluting and non-polluting sectors of the economy (e.g., manufacturing and services).

Fig. 1c illustrates the time paths of the clean and dirty capital stocks. The optimal development path is associated with a monotonically increasing clean capital stock over the simulated horizon and a non-monotonic time path for the dirty capital stock. After an initial period of accumulation of dirty capital, the dirty capital stock adjusts downward to a long-run steady-state value associated with a pristine environment. Notice that the dirty capital stock is above the clean capital stock at the time the EKC commences, and that environmental quality approaches its minimum value in Fig. 1a roughly at the time the capital stocks cross. This indicates the changing nature of the trade-off between sectoral margins in the economy at different relative levels of the clean and dirty capital stocks.

Fig. 1d contains time paths for the various tax rates in the economy. Notice that the optimal fiscal policy involves a nontrivial shift in tax policy for the dirty sector. Initially, investment in dirty capital is subsidized at nearly the same rate as clean capital. Unlike the time path for the tax on clean capital, however, which is relatively flat, the optimal tax on dirty capital increases over time in the development region of the economy. This trend captures an anticipation effect of the type described by Farzin [9] for the case of an environmental stock externality. ${ }^{22}$ Then, at a date that roughly corresponds to the minimum level of environmental quality, the optimal tax on dirty capital adjusts sharply upward, and subsequently declines to the long-run optimal level. A significant policy correction is required to produce the $\mathrm{EKC}$, even when the clean and dirty sectors are symmetric.

The relative rate of growth for clean and dirty output in Fig. 1e illustrates how the economic development pattern depends on the rates of the investment taxes. Dirty output grows more slowly than clean output in the developing region under symmetric conditions because the planner anticipates the change in social investment incentives set to occur in the advanced economy. The rate of dirty output growth tails down with the upward trend in the dirty capital investment tax, achieves a minimum value that mirrors the peak in the investment tax on dirty capital and then adjusts upward to a steady state, zero growth position. The clean capital growth rate, in contrast, remains relatively constant over the simulated horizon.

Fig. 1f compares the simulated consumption paths for the dirty good, the clean good, and the composite consumption commodity. The trends are qualitatively similar to the time paths for sectoral income. ${ }^{23}$

The effect of various changes in the baseline parameter values are described in Fig. 2. These changes correspond to three different types of effects that favor dirty-sector development relative to clean-sector development: (i) dirty consumption is preferred to clean consumption $\left(\rho_{\mathrm{d}}=\right.$ $\left.1-\rho_{\mathrm{c}}=0.6\right)$; (ii) dirty output is more productive than clean output $\left(A_{1 \mathrm{~d}}=(1.10) A_{1 \mathrm{c}}\right)$; and (iii) dirty investment creates dirty capital more readily than does clean investment $\left(A_{3 \mathrm{~d}}=(1.01) A_{3 \mathrm{c}}\right)$. $^{24}$ Fig. 2a compares the time path for environmental quality under each of these three effects to the

\footnotetext{
${ }^{22}$ The environmental sink can be interpreted as an exhaustible resource in the developing economy.

${ }^{23}$ At a constant income tax, sectoral consumption is proportional to sectoral output in (11).

${ }^{24}$ For larger magnitude adjustments in these parameters, the model fails to converge to the long-run equilibrium values described above.
} 

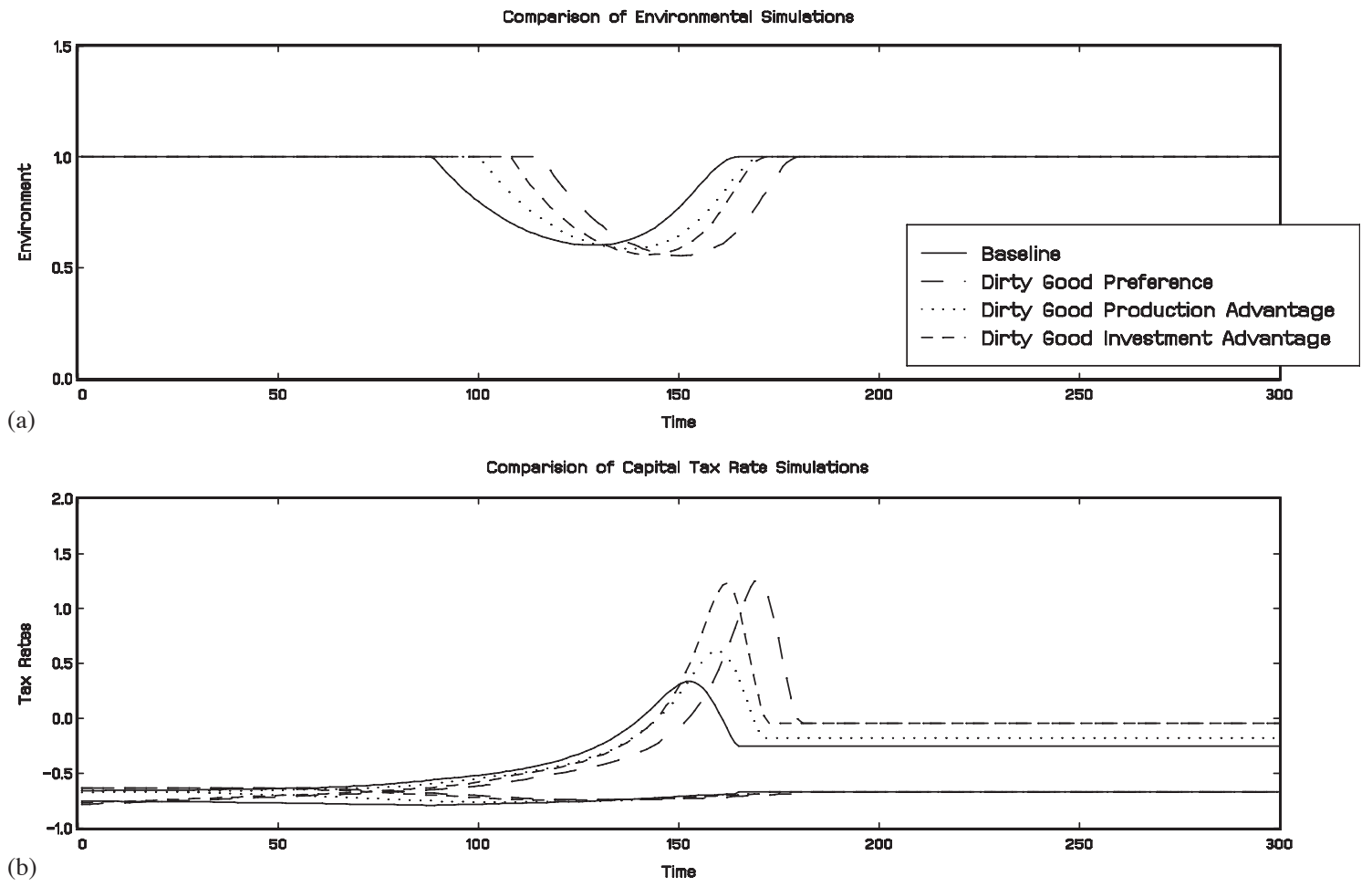

Fig. 2.

baseline calibration. The qualitative features of the development paths are similar in all cases to the baseline model and indicate a U-shaped time pattern for environmental quality over a period of monotonically increasing income.

Fig. $2 \mathrm{~b}$ compares time paths for the capital investment taxes. The time paths broadly illustrate the evolution of the optimal policies under favorable dirty-sector conditions, although we have made no attempt to restrict the regulatory structure to policies that levy capital investment taxes below the unit value. In all cases, the investment tax on clean capital remains fairly stable across the time horizon, but the optimal tax on dirty capital investment spikes upwards in a pronounced fashion relative to the baseline case. The notable feature of these time paths is that, under favorable conditions in the dirty sector, the upward revision in the tax on dirty capital during the EKC amplifies the more modest adjustment from the baseline level that is required by each policy in the long run.

\subsection{The role of endogenous labor supply}

We have discussed three ingredients that are necessary to produce an EKC: (i) dirty output is bounded, (ii) clean output grows endogenously, (iii) and an increase in dirty capital reduces the rate of growth of clean goods. The most direct way to include these ingredients in a model is to specify a separate production externality in each sector and link each externality back to the dirty capital stock. Under exogenous labor supply, a model 
that introduces these ingredients directly would produce the EKC through precisely the same trade-off described here between the level effect and the growth effect. Endogenous labor supply is not qualitatively important for the $\mathrm{EKC}$ if environmental quality is a necessary input for both types of goods.

Nonetheless, endogenous labor supply causes the EKC to emerge in situations where it otherwise would not under exogenous labor supply. For example, suppose the dirty sector represents manufacturing industries that rely on environmental inputs for production, whereas the clean sector represents service industries that do not. An EKC no longer occurs under exogenous labor supply. Capital employed in the manufacturing sector would generate pollution that bounds the output of manufactured goods, as required by condition (i), but pollution emitted by the manufacturing industries would now have no adverse implications for growth in the service industries, violating condition (iii). A model with exogenous labor would produce only a level effect and not a growth effect in this economy, and as a consequence, pollution would either rise monotonically in the advanced economy or else not occur at all.

When environmental quality is a necessary input for only one type of good, the EKC can emerge under endogenous labor supply. Consider again the example of manufacturing and services. Under endogenous labor supply conditions, pollution emitted by the manufacturing industries reduces labor market productivity in the manufacturing sector, which results in a smaller equilibrium labor market allocation. To the extent that manufacturing and services compete for a common pool of labor, this labor market adjustment decreases equilibrium output in both the manufacturing sector and the service sector of the economy. Pollution now dampens the endogenous growth rate in the service sector indirectly through the labor market allocation, which satisfies condition (iii). Under endogenous labor supply, the economy meets all three necessary conditions for the EKC.

Endogenous labor supply conditions also bound economic growth in cases where unbounded endogenous growth would otherwise occur. To see this, notice that if pollution commences in the manufacturing industries under exogenous labor supply, it never becomes optimal to clean it up, but the service sector nonetheless continues to grow endogenously in the long run. Under endogenous labor supply, these outcomes cannot simultaneously occur. Either the economy ultimately cleans up pollution to emphasize the long-run growth of services, which produces the $\mathrm{EKC}$, or the economy fuels capital accumulation in the manufacturing sector to a point that stalls the endogenous growth of services.

To see this scenario more concretely, consider the limiting case of the model in which labor supply is exogenous $(\gamma \rightarrow \infty)$. Note that the EKC can emerge under exogenous labor supply when a separate production externality impacts each sector, because $\lim _{\gamma \rightarrow \infty} \varepsilon_{j}=\theta_{j}$ for $j=\mathrm{d}$, c. If both $\theta_{\mathrm{d}}>0$ and $\theta_{\mathrm{c}}>0$, then dirty output is bounded in (15), as required by condition (i), and dirty capital adversely affects the rate of clean output growth in (16), as required by condition (iii). If clean output growth occurs at a sufficiently high rate in the advanced economy, the EKC is produced whenever the level effect initially dominates the growth effect (in utility terms). However, notice that if $\theta_{\mathrm{d}}=0$ the dirty sector has the potential for unbounded output growth in (15), which violates condition (i), and if $\theta_{\mathrm{c}}=0$, dirty capital has no adverse implications for growth of clean output in (16), which violates condition (iii). Hence, the EKC cannot occur under exogenous labor supply when a production externality impacts only one sector of the economy. 
Under endogenous labor supply $(\gamma<\infty)$, the labor market equilibrium generates an additional feedback mechanism for the EKC. If $\theta_{j}=0$ in sector $j$, then $\varepsilon_{j}=\theta_{i} \rho_{i}\left(\frac{1-\alpha}{\gamma+\alpha-1}\right)$ for $i \neq j, j=\mathrm{d}$, c. A production externality in a single sector of the economy always works its way into both sectors through the adjustment in the labor market equilibrium, which simultaneously produces all three necessary conditions for the EKC. The EKC emerges in an economy with endogenous labor in cases where it otherwise would not if labor was supplied exogenously.

\section{Conclusion}

The socially optimal pattern of economic development under a production externality depends on a dynamic trade-off between two margins associated with investment in dirty capital. The accumulation of dirty capital produces a positive level effect on utility through its contribution to dirty consumption but adversely affects environmental quality and has negative implications for growth in the clean sector. For various parameterizations of the model, these margins adjust in a manner that directs the economy to a socially optimal development pattern consisting of an initial period of low capital stocks, in which dirty goods are emphasized, followed by a transition to clean goods at higher levels of capitalization. Numerical simulation of such a path reveals that the transitional dynamics involve a U-shaped pattern of environmental quality decline and recovery over a period of monotonically increasing income.

In a second-best policy setting with endogenous labor supply, distortionary taxes produce an additional channel for the EKC to arise through intersectoral spillovers linked to equilibrium labor market participation. With endogenous labor supply, a negative production externality always involves both sectors of the economy, and this produces a dynamic tension between dirtysector consumption and clean-sector growth that is capable of generating non-monotonic time paths for the tax on dirty capital, for the stock of dirty capital, and for environmental quality.

Ultimately, the relationship between optimal economic growth and the environment under a production externality depends on several features that determine the relative level of capitalization in the clean and dirty sectors of an advanced economy. These features include the size of the environmental effects introduced by dirty capital, the social discount rate, and the capacity of the environment to assimilate pollution in an initial development phase. If these features align to produce a sufficiently high level of clean output relative to dirty output as pollution begins to exceed its natural sinks, then the shift to clean technologies is immediate. If the level of clean output is sufficiently small relative to the level of dirty output, then the optimal development pattern fuels accumulation of dirty capital and degrades environmental quality to a level that crowds out endogenous growth in the clean sector and bounds economic output. Only for intermediate levels of relative clean and dirty capitalization does the EKC appear.

Our model also shows that an EKC need not develop as per-capita income increases. Indeed, the model cautions against implementing myopic environmental policies that seek to "grow first, then clean up later." When a developing country emphasizes dirty techniques over clean techniques based on their greater potential for short-term output growth, this policy can ultimately halt endogenous growth in the economy at a level beneath the threshold where cleaning up pollution makes economic sense. This observation points to a potentially misleading focus in 
the empirical EKC literature on identifying a level of per-capita income that marks the turning point of the EKC.

\section{Acknowledgments}

We thank Brian Copeland, Sjak Smulders, Thomas Renström, seminar participants at UC Berkeley and Tilburg University, and two anonymous referees for detailed comments which have greatly improved the paper. We would also like to thank Jim Ragan for providing a thorough editorial review.

\section{References}

[1] K.J. Arrow, The economic implications of learning by doing, Rev. Econ. Stud. 29 (1962) 155-173.

[2] A.J. Auerbach, Tax reform, capital accumulation, efficiency, and growth, in: H.J. Aaron, W.G. Gale (Eds.), Economic Effects of Fundamental Tax Reform, Brookings Institution, Washington, DC, 1996.

[3] C.L. Ballard, S.G. Medema, The marginal efficiency effects of taxes and subsidies in the presence of externalities, J. Public Econ. 52 (1993) 199-216.

[4] A.L. Bovenberg, S.A. Smulders, Transitional impacts of environmental policy in an endogenous growth model, Int. Econ. Rev. 37 (1996) 861-893.

[5] S.P. Cassou, K.J. Lansing, Optimal fiscal policy, public capital and the productivity slowdown, J. Econ. Dynam. Control 22 (1998) 911-935.

[6] M.A. Cole, A.J. Rayner, J.M. Bates, The environmental Kuznets curve: An empirical analysis, Environ. Devel. Econ. 2 (1997) 401-416.

[7] T.F. Cooley, E.C. Prescott, Economic growth and business cycles, in: T.F. Cooley (Ed.), Frontiers of Business Cycle Research, Princeton University Press, Princeton, NJ, 1995.

[8] B.R. Copeland, M.S. Taylor, Trade, growth, and the environment. J. Econ. Lit. 42 (2004).

[9] Y.H. Farzin, Optimal pricing of environmental and natural resource use with stock externalities, J. Public Econ. 62 (1996) 31-57.

[10] L.H. Goulder, I.W.H. Parry, R.C. Williams III, D. Burtraw, The cost-effectiveness of alternative instruments for environmental protection in a second-best setting, J. Public Econ. 72 (1999) 329-360.

[11] J. Greenwood, R. Rogerson, R. Wright, Household production in real business cycle theory, in: T.F. Cooley (Ed.), Frontiers of Business Cycle Research, Princeton University Press, Princeton, NJ, 1995.

[12] G.M. Grossman, A.B. Krueger, Environmental Impacts of a North American Free Trade Agreement, in: P. Garber (Ed.), The US-Mexico Free Trade Agreement, MIT Press, Cambridge, MA, 1993.

[13] G.M. Grossman, A.B. Krueger, Economic growth and the environment, Quart. J. Econ. 110 (1995) $353-377$.

[14] Z. Hercowitz, M. Sampson, Output growth, the real wage, and employment fluctuations, Amer. Econ. Rev. 81 (1991) 1215-1237.

[15] A. John, R.A. Pecchenino, An overlapping generations model of growth and the environment, Econ. J. 104 (1994) 1393-1410.

[16] L.E. Jones, R. Manuelli, P.E. Rossi, Optimal taxation in models of endogenous growth, J. Polit. Econ. 101 (1993) 485-517.

[17] L.E. Jones, R. Manuelli, P.E. Rossi, On the optimal taxation of capital income, J. Econ. Theory 73 (1997) $93-117$.

[18] L.E. Jones, R. Manuelli, Endogenous policy choice: The case of pollution and growth, Rev. Econ. Dynam. 4 (2001) 369-405.

[19] F.T. Juster, F.P. Stafford, The allocation of time: Empirical findings, behavior models, and problems of measurement, J. Econ. Lit. 29 (1991) 471-522.

[20] A. Levinson, The ups and downs of the environmental Kuznets curve, in: J.A. List, A. de Zeeuw (Eds.), Recent Advances in Environmental Economics, Edward Elgar, Cheltenham, UK, 2002. 
[21] R.E. Lucas Jr., E.C. Prescott, Investment under uncertainty, Econometrica 39 (1971) 659-681.

[22] R.E. Lucas Jr., N.L. Stokey, Optimal fiscal and monetary policy in an economy without capital, J. Monet. Econ. 12 (1983) 55-94.

[23] C.B. Mulligan, Substitution over time: Another look at labor supply over the life cycle, in: B.S. Bernanke, J. Rotemberg (Eds.), NBER Macroeconomics Annual, MIT Press, Cambridge, MA, 1998.

[24] C.B. Mulligan, X. Sala-i-Martin, Transitional dynamics in two-sector models of endogenous growth, Quart. J. Econ. 108 (1993) 739-774.

[25] D.W. Pearce, J.J. Warford, A World Without End: Economics, Environment, and Sustainable Development, Oxford University Press, Oxford, UK, 1993.

[26] J.M. Poterba, The rate of return to corporate capital and factor shares: New estimates using revised national income accounts and capital stock data, NBER Working Paper 6263, 1997.

[27] F.P. Ramsey, A contribution to the theory of taxation, Econ. J. 37 (1927) 47-61.

[28] P. Romer, Increasing returns and long-run growth, J. Polit. Econ. 94 (1986) 1002-1037.

[29] T.M. Seldon, D. Song, Environmental quality and development: Is there a Kuznets curve for air pollution emissions?, J. Environ. Econ. Manage. 27 (1994) 147-162.

[30] N.L. Stokey, Are there limits to growth?, Int. Econ. Rev. 39 (1998) 1-31.

[31] O. Tahvonen, S. Salo, Economic growth and transitions between renewable and nonrenewable energy resources, Europ. Econ. Rev. 45 (2001) 1379-1398.

[32] X. Zhu, Endogenous capital utilization, investor's effort, and optimal fiscal policy, J. Monet. Econ. 36 (1995) 655-677. 